\title{
Assessment of $\mathrm{CHADS}_{2}$ and $\mathrm{CHA}_{2} \mathrm{DS}_{2}$-VASc scores in obstructive sleep apnea patients with atrial fibrillation
}

\author{
Filip M. Szymanski • Krzysztof J. Filipiak • \\ Anna E. Platek • Anna Hrynkiewicz-Szymanska • \\ Grzegorz Karpinski • Grzegorz Opolski
}

Received: 8 May 2014 /Revised: 17 July 2014 / Accepted: 22 July 2014 / Published online: 2 August 2014

(C) The Author(s) 2014. This article is published with open access at Springerlink.com

\begin{abstract}
Purpose Assessment of stroke risk and implementation of appropriate antithrombotic therapy is an important issue in atrial fibrillation patients. Current risk scores do not take into consideration the comorbidities associated with elevated thromboembolic like obstructive sleep apnea (OSA). The aim of the study was to establish whether atrial fibrillation patients with coexisting OSA have higher stroke risk according to $\mathrm{CHADS}_{2}$ and $\mathrm{CHA}_{2} \mathrm{DS}_{2}$-VASc scores.

Methods Two hundred fifty-four consecutive patients hospitalized with a primary diagnosis of atrial fibrillation participated in the study. All patients underwent whole night polygraphy and were scored in both $\mathrm{CHADS}_{2}$ and $\mathrm{CHA}_{2} \mathrm{DS}_{2}$-VASc according to their medical records or de novo diagnosis.

Results The study population was predominantly male ( $65.4 \%$; mean age, $57.5 \pm 10.0$ years) with a high prevalence of hypertension (73.6\%), dyslipidemia (63.4\%), and obesity $(42.9 \%)$. OSA was present in $47.6 \%$ of patients, who more often had history of stroke $(p=0.0007)$. Stroke risk profile assessed by both $\mathrm{CHADS}_{2}$ and $\mathrm{CHA}_{2} \mathrm{DS}_{2}$-VASc scores was higher in patients with OSA ( $1.2 \pm 0.9$ vs. $0.8 \pm 0.6 ; p<0.0001$ and $2.2 \pm 1.7$ vs. $1.5 \pm 1.1 ; p=0.001)$ than without it. Differences in the stroke risk remained significant across different age strata, and the trend for point values in $\mathrm{CHADS}_{2}$ and $\mathrm{CHA}_{2} \mathrm{DS}_{2}$-VASc scores rose along with OSA severity according to the apnea-hypopnea index (AHI; $p$ for trend $<0.001$ ).
\end{abstract}

F. M. Szymanski $(\bowtie) \cdot$ K. J. Filipiak • A. E. Platek · G. Karpinski • G. Opolski

Department of Cardiology, Medical University of Warsaw,

1A Banacha Street, Warsaw 02-097, Poland

e-mail: filip.szymanski@wum.edu.pl

A. Hrynkiewicz-Szymanska

Department of Cardiology, Hypertension and Internal Diseases,

Medical University of Warsaw, Warsaw, Poland
Conclusions OSA was highly prevalent in atrial fibrillation patients. Patients with OSA have higher $\mathrm{CHADS}_{2}$ and $\mathrm{CHA}_{2} \mathrm{DS}_{2}$-VASc scores. Mean $\mathrm{CHADS}_{2}$ and $\mathrm{CHA}_{2} \mathrm{DS}_{2}-$ VASc scores rise with OSA severity. Future studies should prospectively research on potential inclusion of OSA to stroke prediction models.

Keywords Atrial fibrillation - Obstructive sleep apnea . Stroke risk $\cdot \mathrm{CHADS}_{2} \cdot \mathrm{CHA}_{2} \mathrm{DS}_{2}$-VASc

\section{Introduction}

Atrial fibrillation is one of the most common types of arrhythmia. Currently, it occurs in approximately $2 \%$ of the general population, but it is estimated that its incidence will increase even more [1,2]. The presence of the arrhythmia is associated with an elevated risk of cardiovascular events, most of all stroke [3]. It is estimated that approximately one fifth of all strokes is attributable to the atrial fibrillation and, therefore, could be avoided if patients were managed properly [4]. Given the high atrial fibrillation prevalence and disabling consequences of stroke, prevention of the thromboembolic events is currently one of the key issues in treatment of atrial fibrillation patients $[3,5]$.

Current guidelines recommend planning the anticoagulation treatment individually, according to the patients' thromboembolic risk. Two tools recommended to be used in this indication are the $\mathrm{CHADS}_{2}$ and $\mathrm{CHA}_{2} \mathrm{DS}_{2}$-VASc scores. Both tools are based on easy to obtain clinical data including the presence of congestive heart failure, age, diabetes mellitus, sex, history of stroke, or vascular disease. Point values obtained in the $\mathrm{CHADS}_{2}$ and $\mathrm{CHA}_{2} \mathrm{DS}_{2}$-VASc scores give us approximate information of the annual stroke risk and, therefore, indications for anticoagulation treatment $[6,7]$. 
Unfortunately, like most point scores, $\mathrm{CHADS}_{2}$ and $\mathrm{CHA}_{2} \mathrm{DS}_{2}$-VASc are likely to overlook important parameters, including comorbidities associated with elevated thromboembolic risk. One of them is obstructive sleep apnea (OSA), a sleep-disordered breathing with high prevalence in atrial fibrillation patients (estimated to be between 32 and $49 \%$ ) [8]. OSA is strongly associated with hypercoagulation, which has been reported in the literature previously [9-11]. OSA influence strongly also on prevalence of hypertension, sympathetic dysregulation, or many other cardiovascular risk factors, which causes elevated risk of stroke and other thromboembolic events. The strongly elevated thromboembolic risk and mutual exacerbation of the diseases even caused that, recently, atrial fibrillation and OSA have been postulated to be components of one clinical syndrome [12].

We hypothesize that the stroke risk will be higher in patients with OSA and that this relationship will be clearly shown by the results of $\mathrm{CHADS}_{2}$ and $\mathrm{CHA}_{2} \mathrm{DS}_{2}$-VASc scores in both groups of patients. The aim of the study was to determine if the occurrence of OSA in atrial fibrillation patients is associated with higher stroke risk assessed by $\mathrm{CHADS}_{2}$ and $\mathrm{CHA}_{2} \mathrm{DS}_{2}$-VASc scores.

\section{Methods}

\section{Study population}

In accordance with the Declaration of Helsinki, the study protocol was approved by the Regional Ethics Committee. Before the study entry, a written informed consent was obtained from every study participant. Two hundred fifty-four consecutive patients hospitalized in a high-volume, tertiary University Hospital Cardiology Department were enrolled. The cause of admission in every patient was prequalification for atrial fibrillation ablation procedure. Subjects were eligible to participate in this study if they were 18 to 75 years of age without previously diagnosed OSA or central sleep apnea and no current treatment with continuous positive airway pressure (CPAP) device. Exclusion criteria included prior ablation for atrial fibrillation, untreated overt hyper- or hypothyroidism (defined according to current guidelines), myocardial infarction or decompensation of heart failure within 6 months prior to study entry, fatal condition with estimated life expectancy of $\leq 6$ months, presence of contraindications for polygraphy study including acute and/or chronic pulmonary diseases like obstructive pulmonary disease or active tuberculosis, neuromuscular disease, hemochromatosis, severe neurologic, or psychiatric disorders $[13,14]$.

\section{Assessment of atrial fibrillation and cardiovascular risk}

Medical history of patients, including occurrence of cardiovascular risk factors, was taken on admission in every patient by a qualified physician. In the night following the admission, every patient underwent a whole night sleep study using a portable polygraphy device for diagnosing sleep disorder breathing (Embletta Gold; Flaga, Reykjavik, Iceland).

Diagnosis of atrial fibrillation was based on at least one arrhythmia episode recorded in a 24-h ECG Holter monitoring in 6 months prior to the study enrollment. Diagnosis of the arrhythmia was determined with respect to the European Society of Cardiology Guidelines for the management of atrial fibrillation from 2010 and its update from 2012 [3, 5]. Patients included in the study were prequalified for atrial fibrillation ablation; therefore, no permanent atrial fibrillation was diagnosed in the study population (permanent arrhythmia is diagnosed only if it is decided not to pursue rhythm control strategy). Paroxysmal atrial fibrillation was defined as selfterminating, usually within $48 \mathrm{~h}$, which may continue for up to 7 days. Persistent atrial fibrillation was defined when arrhythmia episode either lasted longer than 7 days or required termination by cardioversion either with drugs or by direct current cardioversion [3].

All patients were interviewed for history of cardiac failure, moderate to severe left ventricle systolic dysfunction, hypertension, diabetes, stroke or transient ischemic attack (TIA), and vascular disease (including myocardial infarction, complex aortic plaque, and peripheral artery disease including prior revascularization, amputation due to peripheral artery disease, or its angiographic evidence). Diagnosis of the abovementioned diseases were made basing on eligible medical records, taking prescription drugs applicable for the respective disease (i.e., hypoglycemic agents for diabetes) or as a de novo diagnosis according to current criteria.

\section{Assessment of stroke risk}

The $\mathrm{CHADS}_{2}$ and $\mathrm{CHA}_{2} \mathrm{DS}_{2}$-VASc scores were calculated for every patient based on predefined point systems according to the current guidelines for scoring and diagnosing all mentioned conditions $[6,7]$. In the $\mathrm{CHA}_{2} \mathrm{DS}_{2}$-VASc score, 2 points were assigned if a patient had a history of stroke or TIA or was $\geq 75$ years of age. One point was assigned for the age 65-74 years, female sex, history of hypertension, diabetes, recent cardiac failure, and vascular disease (history of myocardial infarction, presence complex aortic plaque, or peripheral artery disease). In the $\mathrm{CHADS}_{2}$ score, 2 points are assigned for the history of stroke or TIA, and 1 point for each of the following: history of congestive heart failure, diabetes or hypertension, and age $\geq 75$ years. 


\section{Diagnosis of OSA}

Polygraphy used in the study is a level 3 sleep monitoring tool according to the recommendations of the European Respiratory Society and the European Society of Hypertension [15]. This kind of devices record $>4$ channels including channels to detect respiratory movements or respiratory effort, airflow, heart rate, ECG, and oxygen saturation and are used for objective OSA diagnosis confirmation. All polygraphy results were scored manually according to the recommendations of the American Academy of Sleep Medicine by a qualified cardiologist specialized in sleep medicine [16]. Apnea was defined as a complete cessation (residual air flow equal of $<10 \%$ of the preceding stable breathing period) of airflow lasting $\geq 10 \mathrm{~s}$. Obstructive breathing event occurs with complete upper airway obstruction. Hypopnea was defined as a noticeable decrease ( $>30$ and $<90 \%$ ) in the respiratory signal amplitude which lasted for $>10$ and accompanied by desaturation $(\geq 4 \%)$. OSA diagnosis was made when the apnea-hypopnea index (AHI, number of apneas and hypopneas per hour) was $\geq 5$ per hour. Patients with confirmed OSA were subsequently grouped according to OSA severity with $\mathrm{AHI} \geq \mathrm{OSA}$ severity was classified as mild when $\mathrm{AHI} \geq 5$ and $<15$ per hour, moderate when AHI was $\geq 15$ and $\leq 30$ per hour, and as severe when AHI was $>30$ per hour.

\section{Statistical analysis}

Data were tested for normality using the KolmogorovSmirnov test. Continuous data are presented as mean and $95 \%$ confidence intervals (CI), with statistical comparisons performed with the Mann-Whitney test or Student's $t$ test. Categorical variable comparison was made using either the chi-square or Fisher exact tests. A one-way analysis of variance was used to assess the impact of OSA severity according to $\mathrm{AHI}$ on the $\mathrm{CHADS}_{2}$ and $\mathrm{CHA}_{2} \mathrm{DS}_{2}$-VASc scores. A $p$ value of less than 0.05 was considered statistically significant, whereas the confidence intervals were $95 \%$. All statistical calculations were performed using commercially available SAS statistical software version 8.02 (SAS Institute, Inc., Cary, NC, USA).

\section{Results}

The baseline characteristics of the study population are described in Table 1. Of the 254 patients, 88 (34.6\%) were females. Mean age of the study population was $57.5 \pm$ 10.0 years. Hypertension was present in $73.6 \%$ of patients, whereas $63.4 \%$ suffered from dyslipidemia. The prevalence of body mass index (BMI) exceeding criteria for obesity diagnosis $\left(>30 \mathrm{~kg} / \mathrm{m}^{2}\right)$ was $42.9 \%$. Paroxysmal atrial
Table 1 Baseline characteristics of the study population

\begin{tabular}{|c|c|}
\hline Parameter & Value \\
\hline Age (years) & $57.5 \pm 10.0$ \\
\hline Female & $88(34.6 \%)$ \\
\hline Hypertension & $187(73.6 \%)$ \\
\hline Diabetes mellitus & $23(9.1 \%)$ \\
\hline Prior stroke or TIA & $18(7.1 \%)$ \\
\hline Dyslipidemia & $161(63.4 \%)$ \\
\hline Smoking & $26(10.2 \%)$ \\
\hline SBP (mm Hg) & $132.1 \pm 16.9$ \\
\hline DBP (mm Hg) & $80.9 \pm 11.1$ \\
\hline BMI $>30 \mathrm{~kg} / \mathrm{m}^{2}$ & $109(42.9 \%)$ \\
\hline Neck circumference $(\mathrm{cm})$ & $40.3 \pm 3.6$ \\
\hline Waist circumference $(\mathrm{cm})$ & $108.4 \pm 65.7$ \\
\hline Paroxysmal AF & $176(69.3 \%)$ \\
\hline $\mathrm{AHI}<5$ per hour & $133(52.4 \%)$ \\
\hline $\mathrm{AHI} \geq 5$ and $<15$ per hour & $74(29.1 \%)$ \\
\hline $\mathrm{AHI} \geq 15$ and $<30$ per hour & $35(13.8 \%)$ \\
\hline $\mathrm{AHI} \geq 30$ per hour & $12(4.7 \%)$ \\
\hline $\mathrm{CHADS}_{2}$ & $1.0 \pm 0.8$ \\
\hline $\mathrm{CHA}_{2} \mathrm{DS}_{2}$-VASc & $1.8 \pm 1.4$ \\
\hline AHI (per hour) & $8.4 \pm 10.8$ \\
\hline
\end{tabular}

Values are mean $\pm \mathrm{SD}$ or $n(\%)$,

$A F$ atrial fibrillation, $A H I$ apnea-hypopnea index, $B M I$ body mass index, $D B P$ diastolic blood pressure, $S B P$ systolic blood pressure, $S D$ standard deviation, TIA transient ischemic attack

fibrillation was present in the majority of patients $(69.3 \%)$, and for the rest, persistent atrial fibrillation was diagnosed. Mean $\mathrm{CHADS}_{2}$ and $\mathrm{CHA}_{2} \mathrm{DS}_{2}$-VASc scores were, respectively, $1.0 \pm 0.8$ and $1.8 \pm 1.4$. Mean AHI value in the whole study population was $8.4 \pm 10.8$ per hour.

OSA was present in $47.6 \%$ of patients. Details of patients' characteristics according to OSA status are presented in Table 2. Patients with OSA were older (59.6 \pm 7.9 vs. $55.5 \pm$ 11.3 years; $p=0.008)$ and had higher neck ( $41.2 \pm 3.8$ vs. 39.4 $\pm 3.3 \mathrm{~cm} ; p=0.0002)$ and waist circumferences $(108.5 \pm 13.1$ vs. $108.3 \pm 89.2 \mathrm{~cm} ; p<0.0001)$ than patients without OSA. Obesity was diagnosed in more patients in OSA than nonOSA group ( 54.5 vs. $32.3 \% ; p=0.0006)$. Also, the prevalence of other comorbidities was different in patients with and without OSA. Patients with OSA more often were diagnosed with hypertension ( 80.2 vs. $67.7 \% ; p=0.03)$, diabetes mellitus (13.2 vs. $5.3 \% ; p=0.05)$, or had history of stroke (13.2 vs. $1.5 \% ; p=0.0007$ ) than patients without the sleepdisordered breathing condition. The form of arrhythmia that was predominant in OSA patients was persistent atrial fibrillation, whereas in patients without OSA, atrial fibrillation was more often paroxysmal $(p=0.02)$.

General thromboembolic risk profile assessed by both $\mathrm{CHADS}_{2}$ and $\mathrm{CHA}_{2} \mathrm{DS}_{2}$-VASc scores was higher in patients 
Table 2 Patients' characteristics according to the presence of obstructive sleep apnea
Values are mean $\pm \mathrm{SD}$ or $n(\%)$ $A F$ atrial fibrillation, $A H I$ apneahypopnea index, $B M I$ body mass index, $D B P$ diastolic blood pressure, $O S A$ obstructive sleep apnea, $S B P$ systolic blood pressure, $S D$ standard deviation, TIA transient ischemic attack

\begin{tabular}{|c|c|c|c|}
\hline Parameter & Patients without OSA $(n=133)$ & Patients with OSA $(n=121)$ & $p$ value \\
\hline Age (years) & $55.5 \pm 11.3$ & $59.6 \pm 7.9$ & 0.008 \\
\hline Female & $52(39.1 \%)$ & $36(29.8 \%)$ & 0.15 \\
\hline Hypertension & $90(67.7 \%)$ & $97(80.2 \%)$ & 0.03 \\
\hline Diabetes mellitus & $7(5.3 \%)$ & $16(13.2 \%)$ & 0.05 \\
\hline Prior stroke or TIA & $2(1.5 \%)$ & $16(13.2 \%)$ & 0.0007 \\
\hline Dyslipidemia & $84(63.2 \%)$ & $77(63.6 \%)$ & 0.96 \\
\hline Smoking & $16(12.0 \%)$ & $10(8.3 \%)$ & 0.43 \\
\hline $\mathrm{SBP}(\mathrm{mm} \mathrm{Hg})$ & $131.5 \pm 17.0$ & $132.8 \pm 16.8$ & 0.55 \\
\hline DBP (mm Hg) & $80.0 \pm 10.8$ & $82.0 \pm 11.5$ & 0.16 \\
\hline $\mathrm{BMI}>30 \mathrm{~kg} / \mathrm{m}^{2}$ & $43(32.3 \%)$ & $66(54.5 \%)$ & 0.0006 \\
\hline Neck circumference (cm) & $39.4 \pm 3.3$ & $41.2 \pm 3.8$ & 0.0002 \\
\hline Waist circumference $(\mathrm{cm})$ & $108.3 \pm 89.2$ & $108.5 \pm 13.1$ & $<0.0001$ \\
\hline Paroxysmal AF & $101(75.9 \%)$ & $75(62.0 \%)$ & 0.02 \\
\hline $\mathrm{CHADS}_{2}$ & $0.8 \pm 0.6$ & $1.2 \pm 0.9$ & $<0.0001$ \\
\hline $\mathrm{CHA}_{2} \mathrm{DS}_{2}$-VASc & $1.5 \pm 1.1$ & $2.2 \pm 1.7$ & 0.001 \\
\hline
\end{tabular}

with OSA than without it. Mean $\mathrm{CHADS}_{2}$ score in the group with and without OSA was $1.2 \pm 0.9$ and $0.8 \pm 0.6$ points, respectively $(p<0.0001)$. In $\mathrm{CHA}_{2} \mathrm{DS}_{2}$-VASc scale, patients with OSA scored 2.2 \pm 1.7 , while the mean score in non-OSA patients was $1.5 \pm 1.1$ points $(p=0.001)$ (Fig. 1). Differences in thromboembolic risk remained significant even when we analyzed patients in different age strata. $\mathrm{CHADS}_{2}$ score in patients $\leq 65$ years old was higher in OSA than non-OSA patients $(0.7 \pm 0.6$ vs. $1.1 \pm 0.8$ points; $p=0.0004)$, similarly to patients $>65$ years of age $(0.9 \pm 0.5$ vs. $1.7 \pm 1.3$ points; $p=$ 0.03 , respectively) (Fig. 2a). The same trend was observed in respect to the mean $\mathrm{CHA}_{2} \mathrm{DS}_{2}$-VASc score. In patients $\leq 65$ years old, the mean value in OSA patients was $1.2 \pm 0.9$ and in non-OSA patients was $1.7 \pm 1.4$ points $(p=0.03)$. Analysis of the group of patients older than 65 years also showed that OSA patients had higher $(2.5 \pm 1.0$ points $) \mathrm{CHA}_{2} \mathrm{DS}_{2}$ VASc score than non-OSA patients $(3.6 \pm 1.54$ points; $p=$ 0.004) (Fig. 2b).

In the general population, both $\mathrm{CHADS}_{2}$ and $\mathrm{CHA}_{2} \mathrm{DS}_{2}-$ VASc scores seemed to correspond with OSA severity. Dividing the patients into four groups: non-OSA (with AHI $<5$ per hour), mild OSA (AHI $\geq 5$ and $<15$ per hour), moderate OSA (AHI $\geq 15$ and $\leq 30$ per hour), and severe OSA (AHI $>30$ per hour) showed that there was a significant trend towards a rise in $\mathrm{CHADS}_{2}$ ( $p$ for trend $<0.001$ ) and $\mathrm{CHA}_{2} \mathrm{DS}_{2}$-VASc scores ( $p$ for trend $<0.001$ ) (Fig. 3).

To perform a sensitivity analysis, we divided patients into groups with paroxysmal and permanent atrial fibrillation. We observed higher $\mathrm{CHADS}_{2}$ and $\mathrm{CHA}_{2} \mathrm{DS}_{2}$-VASc scores in all OSA patients. In permanent atrial fibrillation patients, the mean $\mathrm{CHADS}_{2}$ score was $0.9 \pm 0.5$ vs. $1.2 \pm 0.8(p=0.3)$ for non-OSA and OSA patients, respectively, and $\mathrm{CHA}_{2} \mathrm{DS}_{2}$ VASc score was $1.7 \pm 1.0$ vs. $1.9 \pm 1.6(p=0.8)$. In the group with paroxysmal atrial fibrillation, the mean $\mathrm{CHADS}_{2}$ was 0.7 \pm 0.6 vs. $1.3 \pm 1.0(p<0.0001)$, and the mean $\mathrm{CHA}_{2} \mathrm{DS}_{2}-\mathrm{VASc}$ was $1.4 \pm 1.1$ vs. $2.4 \pm 1.7(p<0.0001)$ respectively.

\section{Discussion}

$\mathrm{CHADS}_{2}$ and $\mathrm{CHA}_{2} \mathrm{DS}_{2}$-VASc scores are simple risk assessment schemes. $\mathrm{CHADS}_{2}$ was developed basing on the AF Investigators and Stroke Prevention in Atrial Fibrillation (SPAF) Investigators criteria and includes stroke risk factors like recent cardiac failure, hypertension, age $>75$ years, diabetes, and history of stroke or TIA [6]. The presence of those factors showed to be predictive for thromboembolic risk in the population of SPAF trial [17]. In all of the SPAF trials, OSA was not assessed and, therefore, could not be included in the risk model. Risk assessment scheme was developed with data from Euro Heart Survey on Atrial Fibrillation, which again does not include data on OSA [18]. $\mathrm{CHA}_{2} \mathrm{DS}_{2}$-VASc score

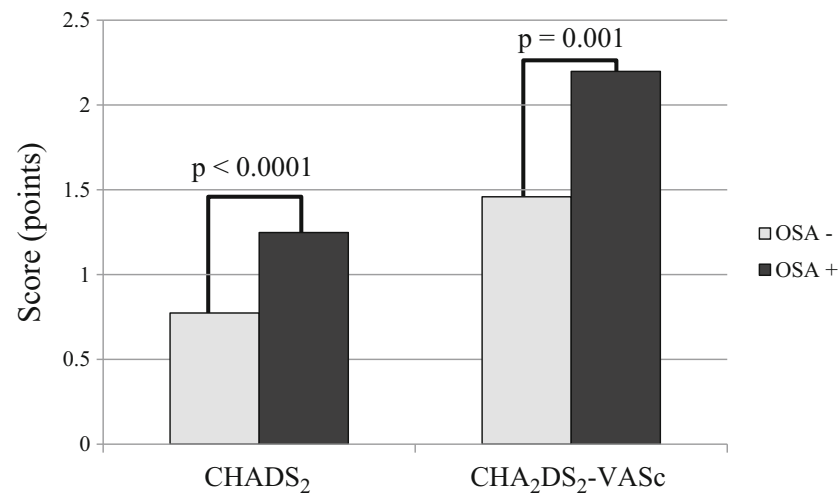

Fig. 1 Mean $\mathrm{CHADS}_{2}$ and $\mathrm{CHA}_{2} \mathrm{DS}_{2}$-VASc scores in patients with and without obstructive sleep apnea (OSA) 

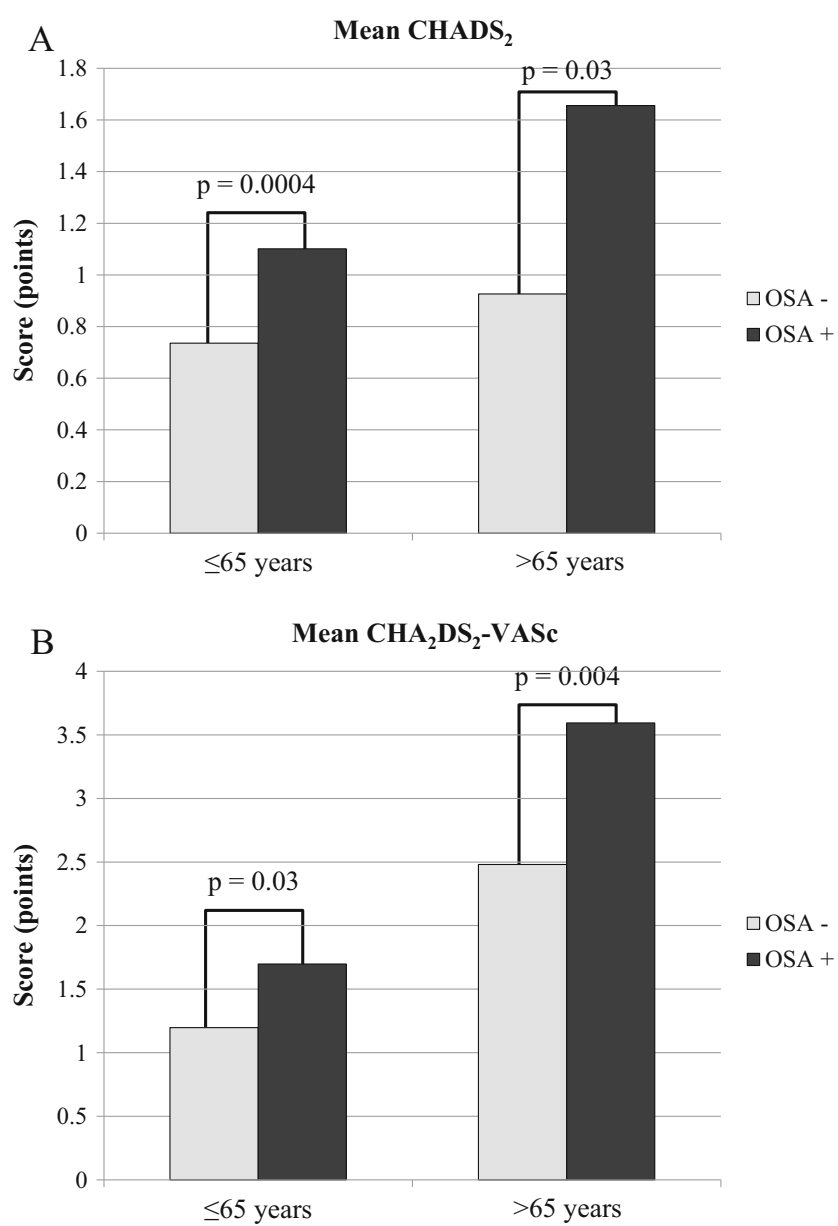

Fig. 2 Relationship of mean obstructive sleep apnea (OSA) with $\mathrm{CHADS}_{2}(\mathbf{a})$ and $\mathrm{CHA}_{2} \mathrm{DS}_{2}$-VASc (b) scores in different age strata

attributes points for history of congestive heart failure, hypertension, diabetes, stroke, vascular disease, age $\geq 75$ or $65-74$, and female sex [7]. Both scores showed to predict incidence of stroke basing on the patient's score [6, 19]. Moreover, they showed value in predicting other complications like pulmonary embolism or coronary artery disease severity [20, 21]. Some authors even postulated that $\mathrm{CHADS}_{2}$ can be useful in predicting ischemic stroke in patients without atrial fibrillation [22]. Both scores are clinically useful, but there are several disparities between them. Current guidelines encourage the use of $\mathrm{CHA}_{2} \mathrm{DS}_{2}$-VASc because some analyses showed that $\mathrm{CHADS}_{2}$ may underestimate stroke risk in patients with lower value range [23]. Nevertheless, both schemes are not free from flaws, and both may underestimate real stroke risk.

Meta-analyses of prospective cohort studies show that OSA patients, similarly to atrial fibrillation patients, are more likely to suffer from stroke [9-11, 24]. Moreover, sleepdisordered breathing is a predictor of all-cause mortality and recurrent vascular events following stroke [25]. In our study, like in the previous observations, the occurrence of OSA was associated with older age and obesity. These two risk factors are associated not only with the occurrence of OSA but also
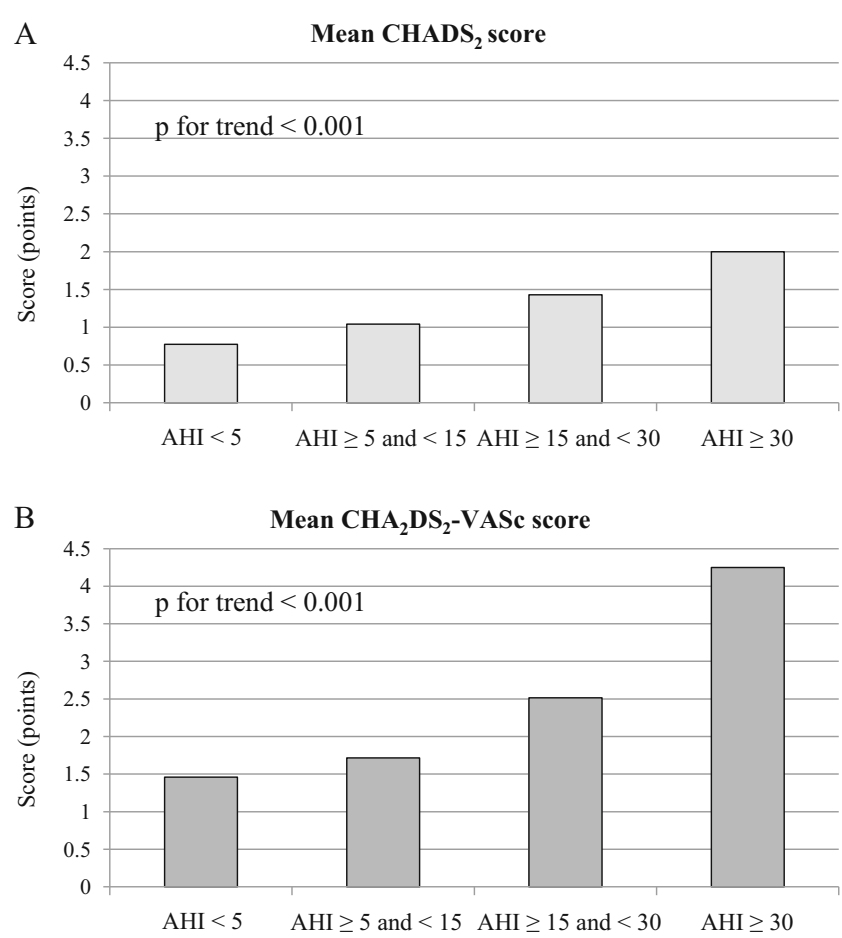

Fig. 3 Trends in $\mathrm{CHADS}_{2}$ (a) and $\mathrm{CHA}_{2} \mathrm{DS}_{2}$-VASc (b) scores according to obstructive sleep apnea (OSA) severity

the promotion of atrial fibrillation in the general population [2, $26,27]$. There is a blurred line between concepts that OSA promotes atrial fibrillation, atrial fibrillation contributes to OSA development, or both conditions are caused by other common risk factors [8]. Nevertheless, cardiovascular risk, including stroke risk, is altered additively by both diseases.

The concept of adding OSA as a stroke risk factor to the $\mathrm{CHADS}_{2}$ has been previously proposed by Yazdan-Ashoori and Baranchuk [28], but literature lacked evidence from trials that were designed to support the thesis. It was proposed to include OSA in the CHADS 2 score by allocating 1 point for OSA, and as the authors said, to rename the score $\mathrm{CHADSS}_{2}$ by adding an extra "S" for sleep apnea. The design of the present trial also does not provide an answer if OSA is an independent risk factor for future stroke and/or mortality in this group of patients, but it highlights two problems. First of all, in our study, OSA patients had higher $\mathrm{CHADS}_{2}$ and $\mathrm{CHA}_{2} \mathrm{DS}_{2}$-VASc scores even irrespectively of age group. This is caused by higher morbidity rates and worse general risk profile in this group of patients. Second of all, OSA is a strong stroke risk factor. Patients afflicted with OSA already are at higher risk of stroke when we do not incorporate OSA as an additional factor in the risk prediction model; it is possible that we can oversee some OSA patients with low $\mathrm{CHADS}_{2}$ and $\mathrm{CHA}_{2} \mathrm{DS}_{2}$-VASc scores who would benefit from anticoagulation therapy.

The newest data show that in spite of the current guidelines, many patients with atrial fibrillation in whom anticoagulation is required do not receive proper treatment in many European 
countries [29, 30]. In many cases, patients with atrial fibrillation are undertreated, and many of the strokes associated with OSA could have been avoided by proper risk assessment and more aggressive treatment. Some authors even propose for active screening for atrial fibrillation in all OSA patients, saying that in this high-risk group, this kind of intervention would benefit in stroke rate reduction [31]. OSA screening is easy and widely applicable, while confirmation of the diagnosis with polygraphy or polysomnography becomes more accessible.

In conclusion, OSA was highly prevalent in atrial fibrillation patients. Patients with OSA have higher $\mathrm{CHADS}_{2}$ and $\mathrm{CHA}_{2} \mathrm{DS}_{2}$-VASc scores. Mean $\mathrm{CHADS}_{2}$ and $\mathrm{CHA}_{2} \mathrm{DS}_{2}$-VASc scores rise with OSA severity assessed by AHI. OSA can be a predictor of higher stroke risk in atrial fibrillation patients. All atrial fibrillation patients with OSA should be monitored more carefully for stroke risk factors and promptly introduced with anticoagulation therapy if needed. Further studies are needed to decide if OSA carries a risk beyond its most often comorbidities incorporated in the CHADS 2 and $\mathrm{CHA}_{2} \mathrm{DS}_{2}$-VASc scores and if it should be included in the risk prediction schemes.

Acknowledgments This study was supported by grants from the Polish Cardiac Society in 2011-2013 and did not receive funding or grants from pharmaceutical or other industrial corporations.

Conflict of interest The authors have no conflicts of interest to disclose.

Open Access This article is distributed under the terms of the Creative Commons Attribution License which permits any use, distribution, and reproduction in any medium, provided the original author(s) and the source are credited.

\section{References}

1. Stewart S, Hart CL, Hole DJ, McMurray JJ (2001) Population prevalence, incidence, and predictors of atrial fibrillation in the Renfrew/Paisley study. Heart 86:516-521

2. Go AS, Hylek EM, Phillips KA, Chang Y, Henault LE, Selby JV, Singer DE (2001) Prevalence of diagnosed atrial fibrillation in adults: national implications for rhythm management and stroke prevention: the AnTicoagulation and Risk Factors in Atrial Fibrillation (ATRIA) Study. JAMA 285:2370-3275

3. European Heart Rhythm Association, European Association for Cardio-Thoracic Surgery, Camm AJ, Kirchhof P, Lip GY, Schotten U, Savelieva I, Ernst S, Van Gelder IC, Al-Attar N, Hindricks G, Prendergast B, Heidbuchel H, Alfieri O, Angelini A, Atar D, Colonna P, De Caterina R, De Sutter J, Goette A, Gorenek B, Heldal M, Hohloser SH, Kolh P, Le Heuzey JY, Ponikowski P, Rutten FH (2010) Guidelines for the management of atrial fibrillation: the Task Force for the Management of Atrial Fibrillation of the European Society of Cardiology (ESC). Eur Heart J 31:2369-2429

4. Kirchhof P, Auricchio A, Bax J, Crijns H, Camm J, Diener HC, Goette A, Hindricks G, Hohnloser S, Kappenberger L, Kuck KH, Lip GY, Olsson B, Meinertz T, Priori S, Ravens U, Steinbeck G, Svernhage E, Tijssen J, Vincent A, Breithardt G (2005) Outcome parameters for trials in atrial fibrillation: executive summary. Recommendations from a consensus conference organized by the German Atrial Fibrillation Competence NETwork (AFNET) and the European Heart Rhythm Association (EHRA). Eur Heart J 28:2803-2817
5. Camm AJ, Lip GY, De Caterina R, Savelieva I, Atar D, Hohnloser $\mathrm{SH}$, Hindricks G, Kirchhof P, ESC Committee for Practice Guidelines (CPG) (2012) 2012 focused update of the ESC Guidelines for the management of atrial fibrillation: an update of the 2010 ESC Guidelines for the management of atrial fibrillation. Developed with the special contribution of the European Heart Rhythm Association. Eur Heart J 33:2719-2747

6. Gage BF, Waterman AD, Shannon W, Boechler M, Rich MW, Radford MJ (2001) Validation of clinical classification schemes for predicting stroke: results from the National Registry of Atrial Fibrillation. JAMA 285:2864-2870

7. Lip GY, Nieuwlaat R, Pisters R, Lane DA, Crijns HJ (2010) Refining clinical risk stratification for predicting stroke and thromboembolism in atrial fibrillation using a novel risk factor-based approach: the Euro Heart Survey on atrial fibrillation. Chest 137:263-272

8. Todd K, McIntyre WF, Baranchuk A (2010) Obstructive sleep apnea and atrial fibrillation. Nat Sci Sleep 2:39-45

9. Dong JY, Zhang YH, Qin LQ (2013) Obstructive sleep apnea and cardiovascular risk: meta-analysis of prospective cohort studies. Atherosclerosis 229:489-495

10. Yaggi HK, Concato J, Kernan WN, Lichtman JH, Brass LM, Mohsenin V (2005) Obstructive sleep apnea as a risk factor for stroke and death. N Engl J Med 353:2034-2041

11. Hrynkiewicz-Szymanska A, Szymanski FM, Filipiak KJ, Grabowski M, Dąbrowska-Kugacka A, Karpinski G, Opolski G (2011) Can obstructive sleep apnea be a cause of in-stent thrombosis? Sleep Breath 15:607-609

12. Szymanski FM, Puchalski B, Filipiak KJ (2013) Obstructive sleep apnea, atrial fibrillation, and erectile dysfunction: are they only coexisting conditions or a new clinical syndrome? The concept of the OSAFED syndrome. Pol Arch Med Wewn 123:701-707

13. Garber JR, Cobin RH, Gharib H, Hennessey JV, Klein I, Mechanick J, Pessah-Pollack R, Singer PA, Woeber KA, American Association of Clinical Endocrinologists and American Thyroid Association Taskforce on Hypothyroidism in Adults (2012) Clinical practice guidelines for hypothyroidism in adults: cosponsored by the American Association of Clinical Endocrinologists and the American Thyroid Association. Thyroid 22:1200-1235

14. Bahn Chair RS, Burch HB, Cooper DS, Garber JR, Greenlee MC, Klein I, Laurberg P, McDougall IR, Montori VM, Rivkees SA, Ross DS, Sosa JA, Stan MN, American Thyroid Association; American Association of Clinical Endocrinologists (2011) Hyperthyroidism and other causes of thyrotoxicosis: management guidelines of the American Thyroid Association and American Association of Clinical Endocrinologists. Thyroid 21:593-646

15. Parati G, Lombardi C, Hedner J, Bonsignore MR, Grote L, Tkacova R, Lévy P, Riha R, Bassetti C, Narkiewicz K, Mancia G, McNicholas WT, EU COST Action B26 Members (2013) Recommendations for the management of patients with obstructive sleep apnoea and hypertension. Eur Respir J 41:523-538

16. Epstein LJ, Kristo D, Strollo PJ Jr, Friedman N, Malhotra A, Patil SP, Ramar K, Rogers R, Schwab RJ, Weaver EM, Weinstein MD, Adult Obstructive Sleep Apnea Task Force of the American Academy of Sleep Medicine (2009) Clinical guideline for the evaluation, management and long-term care of obstructive sleep apnea in adults. J Clin Sleep Med 5:263-276

17. Hart RG, Pearce LA, McBride R, Rothbart RM, Asinger RW (1999) Factors associated with ischemic stroke during aspirin therapy in atrial fibrillation: analysis of 2012 participants in the SPAF I-III clinical trials. The Stroke Prevention in Atrial Fibrillation (SPAF) Investigators. Stroke 30:1223-1229

18. Nieuwlaat R, Capucci A, Camm AJ, Olsson SB, Andresen D, Davies DW, Cobbe S, Breithardt G, Le Heuzey JY, Prins MH, Lévy S, Crijns HJ, European Heart Survey Investigators (2005) Atrial fibrillation management: a prospective survey in ESC member countries: the Euro Heart Survey on Atrial Fibrillation. Eur Heart J 26:2422-2434 
19. Lip GY, Frison L, Halperin JL, Lane DA (2010) Identifying patients at high risk for stroke despite anticoagulation: a comparison of contemporary stroke risk stratification schemes in an anticoagulated atrial fibrillation cohort. Stroke 41:2731-2738

20. Saliba W, Rennert G (2014) CHA2DS2-VASc score is directly associated with the risk of pulmonary embolism in patients with atrial fibrillation. Am J Med 127:45-52

21. Cetin M, Cakici M, Zencir C, Tasolar H, Baysal E, Balli M, Akturk E (2013) Prediction of coronary artery disease severity using CHADS2 and CHA2DS2-VASc scores and a newly defined CHA2DS2-VAScHS score. Am J Cardiol 113:950-956

22. Welles CC, Whooley MA, Na B, Ganz P, Schiller NB, Turakhia MP (2011) The CHADS 2 score predicts ischemic stroke in the absence of atrial fibrillation among subjects with coronary heart disease: data from the Heart and Soul Study. Am Heart J 162:555-561

23. Coppens M, Eikelboom JW, Hart RG, Yusuf S, Lip GY, Dorian P, Shestakovska O, Connolly SJ (2013) The CHA2DS2-VASc score identifies those patients with atrial fibrillation and a CHADS2 score of 1 who are unlikely to benefit from oral anticoagulant therapy. Eur Heart J 34:170-176

24. Li M, Hou WS, Zhang XW, Tang ZY (2014) Obstructive sleep apnea and risk of stroke: a meta-analysis of prospective studies. Int J Cardiol 172:466-469

25. Birkbak J, Clark AJ, Rod NH (2014) The effect of sleep disordered breathing on the outcome of stroke and transient ischemic attack: a systematic review. J Clin Sleep Med 10:103-108
26. Peppard PE, Young T, Palta M, Dempsey J, Skatrud J (2000) Longitudinal study of moderate weight change and sleepdisordered breathing. JAMA 284:3015-3021

27. Nabauer M, Gerth A, Limbourg T, Schneider S, Oeff M, Kirchhof P, Goette A, Lewalter T, Ravens U, Meinertz T, Breithardt G, Steinbeck G (2009) The Registry of the German Competence NETwork on Atrial Fibrillation: patient characteristics and initial management. Europace 11:423-434

28. Yazdan-Ashoori P, Baranchuk A (2011) Obstructive sleep apnea may increase the risk of stroke in AF patients: refining the CHADS2 score. Int J Cardiol 146:131-133

29. Lip GY, Laroche C, Dan GA, Santini M, Kalarus Z, Rasmussen LH, Oliveira MM, Mairesse G, Crijns HJ, Simantirakis E, Atar D, Kirchhof P, Vardas P, Tavazzi L, Maggioni AP (2014) A prospective survey in European Society of Cardiology member countries of atrial fibrillation management: baseline results of EURObservational Research Programme Atrial Fibrillation (EORP-AF) Pilot General Registry. Europace 16:308-319

30. Derezinski T, Wasikowska B, Strzebonski B, Jawien A (2013) Outpatient oral anticoagulation in Poland in 2012: a single centre experience. Kardiol Pol 71:1135-1139

31. Wilson D, Frontera A, Thomas G, Duncan E (2014) Screening for atrial fibrillation in patients with obstructive sleep apnoea to reduce ischaemic strokes. Int J Cardiol 172: $297-298$ 